\title{
Acute Physiological Effects of Small-Sided Games Applied on the Hearing-Impaired National Team Soccer
}

\author{
Ercan Gür ${ }^{1}$, Ilker Püren ${ }^{1}$ \\ ${ }^{1}$ Faculty of Sport Sciences, Firat University, Turkey \\ Correspondence: Ercan Gür, Faculty of Sport Sciences, Firat University, Turkey.
}

Received: January 15, 2019

Accepted: January 29, 2019

Online Published: January 30, 2019

doi:10.11114/jets.v7i3S.4006

URL: https://doi.org/10.11114/jets.v7i3S.4006

\begin{abstract}
The purpose of this study is to determine whether there is a difference between physiological responses to the small-sided games often applied during soccer trainings by changing the dimensions of the fields, the number of players, duration and the rules of the games.

16 sports people, who play soccer in Turkey Hearing- Impaired National soccer Team, having 31, 38 $\pm 6,02$ of age, $177,13 \pm 4,38 \mathrm{cms}$ of height, $74,22 \pm 4,44 \mathrm{kgs}$ of bodily weight, volunteered for this research. The subjects were made to play free games with the intervals of 2 days, in different periods of $4 \times 4$, in the fields of $36 \mathrm{mx} 24 \mathrm{~m}$, in 24 minutes in total in the forms of $1 \times 24,2 \times 12,4 \times 6$ and $6 \times 4$. After each game, a rest period of two days, and between the sets, a rest period of 4 minutes was given. Through anthropometric measurements of the subjects, their lactic acid levels in blood and the number of heart beats after small-sided games were determined. Also the difficulty levels perceived were determined with BORG scale. The data were transferred to IBM SPSS statistics 22 program and the analyses were completed. Friedman test was used to have a look whether there was a difference between descriptive statistics and dependent groups for continuous variables.

At the end of the small-sided games applied in different periods and repetitions, a statistical meaningfulness was determined in the comparison of the speed of the heartbeat of the subjects that participated in the $\operatorname{study}(\mathrm{P}<0.001)$. While a meaningfulness was determined in the comparison of the lactic acid amounts that appeared in the subjects $(\mathrm{P}<0.01)$; there was no statistical meaningfulness in the comparison of the perceived difficulty level of the small-sided games played.
\end{abstract}

Keywords: soccer, hearing-impaired, small-sided games

\section{Introduction}

There is a growing interest among researchers and appliers in small-sided games that are used as a method of facilitating and developing the soccer skills for individuals in every age and skill level. Small-sided games, which are used as game-based training in team sports for the purpose of developing skills and physical appropriateness, are also used to reinforce movement and decision skills, condition and physical appropriateness.

In sports that necessitate maximum or a high level of performance, more benefit is obtained when the qualities of the training are in a similar level to conditions of the competition (Bompa, 1998). If we reflect this thought on soccer, trainings carried out by shortening the dimensions of the field and decreasing the number of players in teams are called small-sided games.

These games are drills carried out to obtain more productivity during trainings for the purpose of developing skills and aptitude, interpreting the game, increasing the level of stamina and reinforcing the skill of deciding truly, fulfilling all the needs of the training (Aguiar, 2012). For this reason, small-sided games played with different rules of soccer are commonly used for the purpose of developing condition levels, the capacity for endurance, and also technical and tactical performance (Aktas, 2013).

Studies made in recent years have shown that not only roadwork but also trainings made with a ball affect endurance performance in a positive way. In one of these studies, it was seen that there was a positive increase in the endurance performance at the end of the endurance trainings applied on small groups, where there were small-sided games and dribbling carried out with a ball (Hoff, 2002). 
The violence and intensity of such trainings carried out with a ball may be determined by a lot of different physiological, technical and tactical factors such as the shape of the field, the dimensions of the field, why they are carried out, time intervals of recovery, the rules of the game, the encouragement of the trainer, the usability of the ball in the game, the way in which goals are scored. These trainings may be formed according to norms needed in the direction of these factors (Bangsbo 1994, Hill-Haas ve ark 2009). For the purpose of understanding well the purpose of the small-sided games, it will be beneficial for the trainers to control the whole training themselves (Aguiar, 2012).

When different field dimensions and formats are used in small-sided games, the responses towards received physiological, perceptional and timely-motional activities will also be different. However, there are differences in the results of researches carried out regarding the physiological responses belonging to differences in field dimensions. This, most probably, results from using different fields used in different dimensions (Aguiar, 2012).

\section{Method}

\subsection{The Sample of Study}

The sample group of this study, which was carried out for the purpose of the Comparison of the Acute Physiological Effects and Perceived Difficulty Levels of Small-sided Games Applied on the Hearing-Impaired National Soccer Team Soccers consisted of 20 sportspeople called to the camp of Turkey Hearing-Impaired Soccer National Team. The number was then dropped to 16 as a result of the injury of 4 people. The maximal oxygen capacity of the subjects was determined through Yo-yo Intermitten Recovery 1 Test (YIRT) carried out before the study and groups of four were formed.

The hearing-impaired national soccer team sportspeople that participated in the study were made to read the form of informed volunteer and their approval was obtained and they were included in the study after necessary permits were obtained from the Federation of the Hearing-Impaired.

In this study, help from hearing-impaired instructors working in the Federation of the Hearing-Impaired was received in order to realize the necessary communication with hearing-impaired sportspeople.

For this study, an approval was granted from Firat University Ethics Committee of Non- Entrepreneurial Research, with Meeting Number:15, Decision no: 03 dated 16.09.2014.

\subsection{Measurement Instruments and Material}

\subsubsection{Measurement of Height and Weight}

The height of the subjects was measured through SEKA(Germany) stadiotmeter whose sensitivity is $\pm 1 \mathrm{~mm}$, and their bodily weight was measured through SEKA(Germany)electronic bascule whose sensitivity is $\pm 0,1 \mathrm{~kg}$.

\subsubsection{Yo-Yo Intermittent Recovery 1 Test (YIRT)}

This test is one that first starts with the speed of $10 \mathrm{~km} / \mathrm{h}$ and in which speed regularly increases. The test consists of 20 meters of going and 20 meters of coming back, it is carried out in a manner in which each participant has a rest for 10 seconds in a lounge of $5+5$ meters at the end of each lap. The test was used to estimate the oxygen consumption levels of the subjects. If the sportsperson cannot enter the field line of 20 meters in the time of the lap at his or her second mistake, his or her test is over and the distance that the sportsperson has covered is recorded as the result of the test. There is just one round trip in total at the first level of the test and the speed is $10 \mathrm{~km} / \mathrm{h}$; at the second level, there is one round trip and the speed is $11,5 \mathrm{~km} / \mathrm{h}$; at the third level, the speed is $13 \mathrm{kmh}$; at the fourth level of the fourth lap, the speed is $13,5 \mathrm{~km} / \mathrm{h}$; at the sixth lap at the fifth level, the speed is $14 \mathrm{~km} / \mathrm{h}$ and at the eighth lap at the sixth level, the speed is $14 \mathrm{kmh}$ and at the sixteenth lap at the seventh level, the speed is $15 \mathrm{~km} / \mathrm{h}$ and the sixteen laps comprise 16 laps at every other level and at every other level, the speed increases by $0,5 \mathrm{kmh}$ gradually and this increase continues until the sportsperson finishes by his or her own will or he or she makes mistakes for two times (Tamer, 2013).

In this test, the study was clarified to the sportspeople by a Hearing-impaired National Team sign language expert that knows sign language well. The sportspeople were made to watch the study beforehand by video. The sportspeople were demonstrated that signal flags were to be lifted up by two trainers simultaneously with the signalisation instead of the system of signalisation and the sportspeople were supposed to be in specified marks each time the signal flags were lifted up. Before the study was started, trial runs were made together with the sportspeople.

\subsubsection{The Number of Heartbeats}

The telemetrical polar (RS400) heartbeat monitor was used for the purpose of determining the number of heartbeats of the subjects. The polar watches and the waist apparatus given to the sportspeople before the test (Polar brand RS 400 model, Polar Electro Oy, Finland) were used in order to determine the number of heartbeats of the sportsmen at each stage of the training. Before the study, the number of heartbeats was recorded by installing the chest apparatus of the heartbeat monitor onto the ribcage of the sportsperson. 
The fact that the sportspeople were hearing-impaired necessitated the presence of the language expert for the hearing-impaired with us always during the study. The mistakes that happened during the study and small reminders were made up for through the language expert for the hearing-impaired.

\subsubsection{Determining the Lactate Level in Blood:}

The LA levels of the sportspeople that joined the small-sided games both before and after all the trainings were measured through lactate analyzer (Lactate Scout, SensLab, Leipzig, Germany). The blood samples were taken from the tips of the earlobes of the sportspeople Tanner, Fuller, Ross. Evaluation of three portable blood lactate analysers: Lactate Pro, Lactate Scout and Lactate Plus. Eur J Appl Physiol, 2010;109:551-9. (Tanner, 2010). During the process of blood-taking, support was received from the health team assigned in Hearing-impaired National Team.

The act of blood taking was carried out through lacytic acid analyser just before $4 \times 4$ small-sided games, 2 minutes before the exercise and within the first 2 minutes at the end of the training.

\subsubsection{Borg Scale Form}

The Determination of the Perceived Difficulty Level (Borg Scale): The Borg Scale(Perceived Difficulty Level, PDL), used for the purpose of determining the violence of the exercise and helping determining the difficulty level of the exercise, was developed by Gunnar Borg in the year 1970. The scale is a survey method which evaluates and grades the difficulty of the exercise in relation to how sportspeople joining the exercise respond to it physiologically and psychologically and according to its own criteria (Borg G, 1982).

\subsubsection{Collection of the Data}

The measurements were made between 15:30-18:00 on grass soccer field. Anthropometric measurements, Yo-yo intermittent recovery test, $4 \times 4$ small-sided games at various periods were completed in 9 days, with intervals of 2 days that followed each other. The measurements carried out and the measurement days are indicated in Chart 1.2. During the tests, the sportspeople were made to do no other training or play no other match.

Table 1. Measurements and Measurement days

\begin{tabular}{cc}
\hline Day of Measurement & Kind of Measurement \\
\hline 1.Day & Anthropomethric measurements, \\
& Yo-Yo Intermittent Recovery 1 Test \\
3.Day & $1 \times 24$ \\
5.Day & $2 \times 12$ \\
7.Day & $4 \times 6$ \\
9.Day & $6 \times 4$ \\
\hline
\end{tabular}

\subsection{Analysis of the Data}

The data obtained was subjected to analysis through IBM SPSS Statistics 22 statistics packaged software. The measurement averages and standard deviations of all the subjects were calculated. In the determination of the difference between the small-sided games, descriptive statistics (median, (minimum, maximum))were given for continuous variables while the study data were being assessed. In order to examine the relationship between parameters, Pearson correlation was applied. The Friedman test was used to have a look whether there was a difference between dependent groups. The importance level of $\mathrm{p}<0,05, \mathrm{p}<0,001, \mathrm{p}<0,01$ is acknowledged as statistically meaningful.

\section{Results}

The findings obtained during the study were obtained from 16 soccer players in the Turkey Hearing-Impaired National Soccer Team.

Table 2. Descriptive Information on the Subjects

\begin{tabular}{|c|c|c|c|c|c|}
\hline Variable & $\mathbf{N}$ & Min. & Maks. & Average & S.S. \\
\hline Age (year) & 16 & 21,00 & 36,00 & 27,00 & 6,02 \\
\hline Height (cms) & 16 & 168,00 & 188,00 & 177,13 & 4,83 \\
\hline Bodily Weight (kgs) & 16 & 67,00 & 82,00 & 74,22 & 4,44 \\
\hline $\mathrm{MaxVO}_{2}(\mathrm{lt} / \mathrm{dk})$ & 16 & 44,96 & 65,12 & 52,82 & 7,37 \\
\hline
\end{tabular}

As the descriptive information on the subjects is examined, as it can be seen in Table 3, the age average was calculated 
as $27,00 \pm 6,02$ years, height as $177,13 \pm 4,83 \mathrm{cms}$, bodily weight as $74,22 \pm 4,44 \mathrm{kgs}$, VKI as $22.49 \pm 2.16 \mathrm{~kg} / \mathrm{m}^{2}$ and lastly their $\mathrm{MaxVO}_{2}$ as $52,82 \pm 7,37 \mathrm{ml} / \mathrm{kg} / \mathrm{min}$, respectively.

Table 3. The Examination of the Difference between Small-sided Games Variables of the Number of Heart Beats

\begin{tabular}{|c|c|c|c|c|c|c|c|c|}
\hline & $\begin{array}{l}\text { Game } \\
\text { Duration }\end{array}$ & $\mathbf{N}$ & Median & Minimum & Maximum & Chi-Square & $\mathbf{P}$ & Difference \\
\hline 1 & 1X24' & 16 & 171,50 & 157,0 & 189,0 & & & \\
\hline 2 & $2 \times 12^{\prime}$ & 16 & 176,00 & 157,0 & 185,0 & 28,933 & $\mathbf{0 , 0 0 0 * * *}$ & $3-1,2$ \\
\hline 3 & $4 \times 6^{\prime}$ & 16 & 167,00 & 155,0 & 176,0 & & & $4-1,2$ \\
\hline 4 & $6 \times 4^{\prime}$ & 16 & 163,50 & 153,0 & 183,0 & & & \\
\hline
\end{tabular}

Meaningfulness between variables was seen as the result of the statistical analysis carried out for the purpose of determining the direction of the difference compared with game durations $(\mathrm{p}<0,001)$. According to this, a difference was determined between $4 \times 6$ and $1 \times 24$ and $2 \times 12,6 \times 4$ and $1 \times 24$ and $2 \times 12$.

Table 4. The Examination of the Difference between Small-sided Games LA Variables

\begin{tabular}{|c|c|c|c|c|c|c|c|c|}
\hline & $\begin{array}{l}\text { Game } \\
\text { Duration }\end{array}$ & $\mathbf{N}$ & Median & Minimum & Maximum & Chi-Square & $\mathbf{p}$ & Difference \\
\hline 1 & $1 \mathrm{X} 24^{\prime}$ & 16 & 6,10 & 2,1 & 9,9 & & & \\
\hline 2 & $2 X 12^{\prime}$ & 16 & 5,90 & 3,1 & 9,2 & 9,171 & $\mathbf{0 , 0 2 7} *$ & $3-1,2$ \\
\hline 3 & $4 \times 6$ & 16 & 5,25 & 2,0 & 8,7 & & & $4-1,2$ \\
\hline 4 & $6 \mathrm{X} 4$ & 16 & 4,05 & 1,7 & 9,6 & & & \\
\hline
\end{tabular}

When we have a look at the rates of game duration- lactic acid, we see a meaningfulness between variables as the result of the statistical analysis carried out in order to determine the direction of the difference $(\mathrm{p}<0,001)$. According to this, a difference was determined between $4 \times 6$ and $1 \times 24$ and 2x12, 6x4 and 1x24 and 2x12.

Table 5. The Examination of the Difference between Small-sided Games BORG Variables

\begin{tabular}{ccccccccc}
\hline $\begin{array}{c}\text { Game } \\
\text { Duration }\end{array}$ & N & Median & Minimum & Maximum & Chi-Square & p & Difference \\
\hline $\mathbf{1}$ & $1 \mathrm{X} 24^{\prime}$ & 16 & 7,00 & 5 & 8 & & & \\
$\mathbf{2}$ & $2 \mathrm{X} 12^{\prime}$ & 16 & 7,00 & 5 & 8 & 3,000 & 0,392 & \\
$\mathbf{3}$ & $4 \mathrm{X} 66^{\prime}$ & 16 & 6,50 & 4 & 9 & & & \\
$\mathbf{4}$ & $6 \mathrm{X} 4^{\prime}$ & 16 & 6,00 & 5 & 9 & & & \\
\hline
\end{tabular}

$\mathrm{p}<0,05$

When we have a look at the relationship between duration and compulsion regarding the sportsmen that joined the study during the small-sided games, while 1X24' BORG median is 7,00, 2X12' BORG median is 7,00, 4X6' BORG median is 6,50 and $6 \mathrm{X} 4$ ' BORG median is 6,00 , respectively. There is no meaningful difference between the variables as the result of the Friedman analysis that was carried out $(\mathrm{p}>0,05)$.

\section{Discussion}

The fact that there are few studies regarding hearing-impaired individuals in the field of small-sided games has obliged us to compare the results that we have obtained with the ones that were obtained from soccerers with no disabilities.

Studies made so far have shown that following and examination of the number of heart beats is important to determining the exercise violence of small-sided games (Hoff, 2002). It was determined that the average heart beat number in soccer matches is $150-180$ beats/min(Bangsbo, 1994).

When we examine the physiological responses to $4 \times 4$ small field games made to play to Turkey Hearing-Impaired National Soccer Team soccerers whose age average is $31.38 \pm 6,02$ with different methods of grouping, while the duration- heart beat number values of the sportspeople are 1X24' HBN median 171,50 beat. min-1, it was calculated that 
2X12' HBS median 176,00 beats. min-1, HBN median is 167,00 beats. min-1 and 6X4' HBN median 163,50 beats/min-1'.

Kelly and Drust (2009), in their study where they researched on the effect of the size of the game field on HBN responses, have specified that the HBN responses to the games decrease as the game field becomes bigger; however, this decrease isn't statistically meaningful after the small-sided games they made play in forms of 4 sets of 4 minutes in

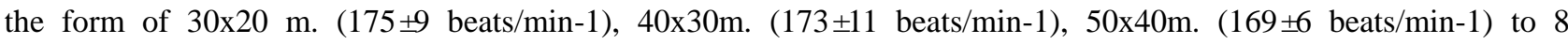
professional soccerers who has an average age of $18 \pm 1$.

Little and Williams (2006), in their study that they carried out with 13 professional soccerers whose age average is $22,8 \pm 4,5$, have specified that the response of 175 beats/min- $1 \mathrm{HBN}$ was given in their $4 \times 4$ small-sided games that were played in a field of $50 \times 30 \mathrm{~m}$ for 3.30 secs and in 5 repetitions.

Diker et al. (2011) applied the $4 \times 4$ small-sided games in two forms of free game and controlled passing in a game field of $24 \times 36 \mathrm{~m}$, with game duration of $4 \mathrm{mns}$, with 4 repetitions, along with $2 \mathrm{mns}$ of resting time. At the end of the research, it was determined that in free game, when sets are examined, \% KAHmax and the heart beat number were 1.set, 180,6 beats $/ \mathrm{min}, 2$. set 184,9 beats $/ \mathrm{min}$, 3 . set 184,1 beats $/ \mathrm{min}$ ve 4 . set 182,8 beats $/ \mathrm{min}$. In the controlled passing game, it was measured that 1 . set was 175,3 beats/min, 2 . set was 180,3 beats $/ \mathrm{min}, 3$. set was 179,8 beats/min, 4 . set was 182,8 beats/min. It was stated that in the heart beat responses to the small-sided games played, they were in higher rate of violence in games played in the form of free game.

Koklu (2008), in the study that was done with 16 young soccer players with an age average of $15,7 \pm 0,4$, a HBN response of $179,3 \pm 8,4$ beats/min- 1 was given to the $4 \times 4$ game that they had them play in a field of $36 \times 24 \mathrm{~m}$, for 4 minutes in 4 sets.

Aroso and his Coleagues(2004), in their study that they did with 14 young soccerers with an average age of 15-16, have specified that the KAHmax response to $4 \times 4$ small-sided game in a field of $30 \times 20 \mathrm{~m}$, in 3 sets and for 6 minutes and with the rule that a player can hit the ball two times consecutively at most is $79 \pm 6 \%$.

Hill-Haas et al.(2008), in their study that they did with 16 young soccer players with an average age of $16,3 \pm 0,6$, a $85 \pm$ $4 \%$ KAHmax response was given to the 4x4 game played in a field of 40x30 m. , for 24 minutes without any breaks.

Fanchini (2010), in his study that he did with 19 soccer players ( $24 \pm 4$ age), has specified that to the $3 \times 3$ small-sided games played in a stable field of $37 \times 31 \mathrm{~m}$, in 3 sets and for 2,4,6 minutes respectively, responses of $82,4 \pm 4,1 ; 85,9 \pm$ 4,$1 ; 85,6 \pm 3,9 \%$ KAHmax were given respectively.

It is observed that changes in dimensions of the field(30x20 HBN:179 $\pm 9,40 \times 30 \mathrm{HBN} 173 \pm 11$ ve 50x40 HBN $169 \pm 6$ $\mathrm{mn} /$ beats)don't change the speed of heart beat and most of the technical necessities observed in small-sided games meaningfully(Kelly, 2009).

LA, which is a byproduct of the trainings, is used as one of the many indications of the exercise done during soccer(Hill-Hass, 2011). As the violence of the exercise increases, so does the demand for energy, and thus does the activity of the anaerobic energy system. The level of LA shows a sharp increase in exercises done for a short time and in a highly violent way. However, it is not in a short time that the body gets rid of LA (Brooks, 2005). The small-sided games applied in this research were examined in terms of duration; the relationship between the duration and LA was also examined.

When we have a look at the rates of the duration and lactic acid of soccerers in our study whose age average is $31.38 \pm$ 6,02, while the $1 \mathrm{X} 24^{\prime} \mathrm{LA}$ median is $6,10 \mathrm{mmol} / \mathrm{L}-1,2 \mathrm{X} 12^{\prime} \mathrm{LA}$ median was measured as $5,90 \mathrm{mmol} / \mathrm{L}-1$, 4X6' LA median as $5,25 \mathrm{mmol} / \mathrm{L}-1$ and $6 \mathrm{X} 4^{\prime} \mathrm{LA}$ median as $4,05 \mathrm{mmol} / \mathrm{L}-1$.

When we examine the LA responses to the small-sided games in literature, in the study that Koklu(2011) did, it is observed that the LA responses of 32 elite young soccerers who have an average age of 16,19 $\pm 0,74$ to the small field games played with the groupings of $\mathrm{MaxVO}_{2}(7,01 \pm 0,73)$ and $\mathrm{MaxVO}_{2}$ Technical $(6,84 \pm 0,64)$ are statistically higher in meaning than the LA responses to the games played with technical grouping $(6,25 \pm 0,72)$ and trainer grouping $(6,41 \pm 0,58)$. These results show that the change in the method of grouping also causes changes in LA responses to the games.

Hill-Haas (2008), in the study that was done with 16 young soccerers having an average age of $16,3 \pm 0,6$, have specified that the LA response of $4,7 \pm 1,6 \mathrm{mmol} / \mathrm{L}-1$ was given to $4 \times 4$ small-sided game played in a field of $40 \times 30 \mathrm{~m}$. for 24 minutes without any breaks.

Aroso et al. (2004), in the study that they did with 14 young soccerers at the ages of 15-16, have specified that the LA response of 2,6 $6 \pm 1,7 \mathrm{mmol} / \mathrm{L}-1$ was given to $4 \times 4$ small-sided game played in a field of 30x20 m, in 3 sets for 6 minutes, with the rule that a player can hit the ball at most two times consecutively. 
Hill-Haas (2009), in their study that they did with 16 young soccerers with an average age of $16,2 \pm 0,2$, have specified

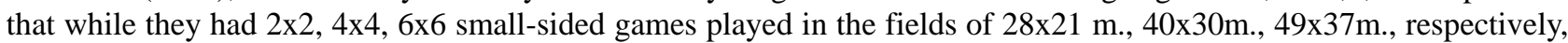

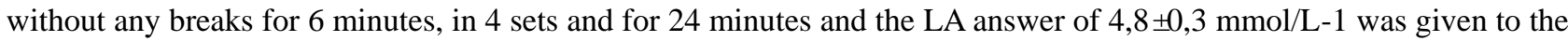
small-sided games of in 4 sets and for 6 minutes, the LA answer of 5,5 $\pm 0,3 \mathrm{mmol} / \mathrm{L}-1$ was given during the small-sided games played for 24 minutes without any breaks.

Koklu (2008), in the study that was done with 16 young soccer players $(15,7 \pm 0,4)$, has specified that the LA answer of $7,2 \pm 2,7 \mathrm{mmol} / \mathrm{L}-1$ was given to the $4 \times 4$ small-sided game played in a field of $36 \times 24 \mathrm{~m}$, in 4 sets of 4 minutes.

Dellal (2011), in his study, carried out the small-sided game for amateur and professional soccer players in a game field of $18 \times 25 \mathrm{~m}$, with four repetitions and with a resting period of 3 minutes. As for the responses given, the LA response of $3.5 \pm 0.2 \mathrm{mmol} / \mathrm{L}-1$ was received from professionals and $4.1 \pm 0.3 \mathrm{mmol} / \mathrm{L}-1$, from amateurs.

In another study, they divided the games into three different kinds as touching the ball only once, twice and free games. The LA levels of $3 \times 3$ small-sided games played in 4 sets and applied in resting periods of 3 minutes were specified as $3,8 \mathrm{mmol} / \mathrm{L}-1,3,3 \mathrm{mmol} / \mathrm{L}-1$ ve 3,0 mmol/L-1, respectively (Dellal, 2011).

Koklu (2012), in his study, when LA answers to the small-sided games were examined, carried out all games in 3 sets and for 2 minutes in the small field, for 3 minutes in the middle-sized field and for 4 minutes in the big field, respectively. In the study, he got the LA answers of 7,8 mmol/L- 1 for $2 \times 2$ small-sided game, $6,8 \mathrm{mmol} / \mathrm{L}-1$ for $3 \times 3$ small-sided game and 6,7 mmol/L-1 for $4 \times 4$ small-sided game( $15 \times 20$ m small, 18 x 24 m middle-sized, 24 x $36 \mathrm{~m}$ big). Koklu (2016), in his study, when higher heart rate and lower blood lactate concentration were found in 3 -a-side and 4-a-side games compared to 2-a-side games.

In the study where LA responses given in small-sided games were examined (Rampinini, 2007), game fields were divided into 3 kinds. Small-sided games where the numbers of players were different were played. These games were carried out in 3 repetitions, with 4 minutes of game duration and with resting periods of 3 minutes. The game fields of $3 \times 3$ small-sided games were divided as $12 \times 20 \mathrm{~m}$ small kind, $15 \times 25 \mathrm{~m}$ middle-sized kind and $18 \times 30 \mathrm{~m}$ big kind. When the LA responses are examined, it was specified that the response of $6,0 \mathrm{mmol} / \mathrm{L}-1$ was given in the small field, $6,3 \mathrm{mmol} / \mathrm{L}-1$ in the middle-sized field and $6,5 \mathrm{mmol} / \mathrm{L} 1$ in the big field.

Unlike LA measurement, PDL is a simple and economic method which enables the determination of the capacity and difficulty of exercise, has no possibility of physically harming the individual (Borg, 1982). It was specified in the research done with HBN and LA that PDL is relevant. It was specified that together with the increasing violence of the exercise, PDL increases (Borg, 1982).

It was calculated that the relations between the duration-PDL of Turkey Hearing-Impaired National Soccer Team sportspeople participating in our study with an average age of $31.38 \pm 6,02$, height of $177.13 \pm 4,83 \mathrm{cms}$, bodily weight of 74,22 $\pm 4,44 \mathrm{kgs}$, in small-sized games are 7,00 with 1X24' BORG median , 7,00 with 2X12' BORG median, 6,50 with 4X6' BORG median ve 6,00 with 6X4' BORG median.

Fanchini (2010), in the study that was done with 19 soccer players with an average age of $24 \pm 4$, has specified that to the $3 \times 3$ small-sided games played in 3 sets of 2,4,6 minutes in a specified, stable field of $37 \times 31 \mathrm{~m}$, PDL responses of 6,7 $\pm 1,6 ; 6,8 \pm 1,4 ; 6,8 \pm 1,5$ in the PDL scale were given respectively.

Hill-Haas (2008), in the study that they did with 16 young soccer players with an average age of $16,3 \pm 0,6$, got the PDL responses of $6-20,12,2 \pm 1,8$ in the $4 \times 4$ small-sided game played in the game field of $40 \times 30 \mathrm{~m}$. and for $24 \times 1$ minutes. In another study that they did (2009) with 16 young soccer players having an average age of 16,2 $\pm 0,2$, they had the

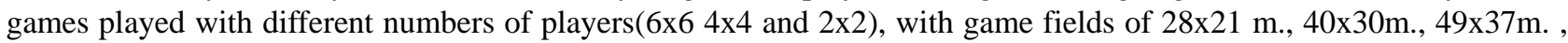
for 24 minutes in total(24x1) and for 6 minutes and in 4 repetitions $(6 \times 4)$ and as a result, in the PDL scale of $6-20,6 \times 4$ gave the PDL response of 11,6 $\pm 0,2$; it was specified that the PDL response of 12,3 $\pm 0,2$ was received in the games of $24 \times 1$ minutes.

Rampini (2007) divided the game field dimensions into 3 kinds and had the small-sided games played in different fashions. There were 3 repetitions, 4 minutes of game and 3 minutes of rest. The game fields of $3 \times 3$ small-sided games were divided as 12x 20 m small kind, $15 \times 25$ m middle-sized kind and $18 \times 30 \mathrm{~m}$ big kind. As a result,it was specified that the PDL responses to the games played in such fields were 8,1 in the small field, 8,4 in the middle-sized field and 8,5 in the big field.

At the end of the study, when the duration in small-sided games and HBN responses are examined, it may be stated that with the prolonging of the duration, the heart beat increases (with the exception of 2/12 small-sided game) directly proportionally; during small-sided games with longer durations, the level of LA is higher when we examine things in terms of LA levels. When examined in terms of PDL, as the duration of small-sided games is prolonged, PDL (with the exception of $6 \mathrm{X} 4$ small-sided game) increases. 
In the studies about the small-sided games, it was aimed that the physiological, technical and tactical responses of soccerers would be assessed when the number of players, dimensions of the field, game rules and the attitude of the trainer were changed. With the alteration of these factors, we can change all physiological and perceptional loads and arrange them according to the criteria that we prefer. However, it is difficult to assess the effect of all these factors separately because of the design of the small-sided games, the condition levels of players, height, age, skills and the encouragement level of the trainer. In the studies about small-sided games, the usage of particular standard conditions will help understand the role of individual differences better and obtain more valid results.

\section{References}

Aguiar, M., Botelho, G., Lago, C., Maças, V., \& Sampaio, J. A. (2012). Review on the effects of soccer small sided games. Journal of Human Kinetics, 33, 103-13. https://doi.org/10.2478/v10078-012-0049-x

Aroso, J., Rebelo, A. N., \& Gomes-Pereira, J. (2004). Physiological impact of selected game-related exercises, Journal of Sports Sciences, 22, 522.

Bangsbo, J. (1994). The physiology of soccer with special reference to intense intermittent exercise, Acta Physiol Scand, $619,1-155$.

Bompa, T. O. (1982). Antrenman kuramı ve yöntemi(Training theory and method), Birinci baskı(first edition), Ankara, Bağırgan Publication, 398-404.

Borg, G. A. (1982). Psychophysical basis of perceived exertion, Med Sci Sports Exerc, 14(5), 377-381. https://doi.org/10.1249/00005768-198205000-00012

Brooks, A., Fahey, T. D., \& Baldwin, K. M. (2005). Exercise Physiology, Hill.

Dellal, A., Chamari, K., Owen, A. L., Wong, D. P., Lago-Penas, C., \& Hill-Haas, S. (2011). Influence of technical instructions on the physiological and physical demands of small-sided soccer games, European Journal of Sport Science, 11(5), 341-346. https://doi.org/10.1080/17461391.2010.521584

Diker, G., Özkamçı, H., \& Kül, S. (2011). The effect of $4 * 4$ small-sided exercises played with controlled passing and free game in stable field on heart beat number and the number of having the ball in young players, Journal of Physical Training and Sport Sciences, 7(3), 105-110.

Fanchini, M., Azzalin, A., Castagna, C., Schena, F., Mcall, A., \& Impellizzeri, F. M. (2011). Effect of bout duration on exercise intensity and technical performance of small-sided games in soccer, J Stren Cond Res, 25, 453-458. https://doi.org/10.1519/JSC.0b013e3181c1f8a2

Hill-Haas, S., Coutts, A., Rowsell, G., \& Dawson, B. (2009). Variability of acute physiological responses and performance profiles of youth soccer players in small-sided games, J Sci Med Sport, 11(5), 487-490. https://doi.org/10.1016/j.jsams.2007.07.006

Hill-Haas, S., Rowsell, G., Dawson, B., \& Coutts, A. (2009). Acute physiological responses and timemotion characteristics of two small-sided training regimes in youth soccer players. J Strength Cond Res, 23(1), 111-115. https://doi.org/10.1519/JSC.0b013e31818efc1a

Hill-Hass S., Dawson, B., Impellizzeri, F. M., \& Coutts, A. (2011). Physiology of small-sided games training in soccer. Sports Med, 4(3), 199-220. https://doi.org/10.2165/11539740-000000000-00000

Katis, A., \& Kellis, E. (2009). Effects of small-sided games on physical conditioning and performance inyoung soccer players, J Sports Sci Med, 8, 374-80.

Köklü, Y. (2012). A comparison of physiological responses to various Intermittent and continuous small sided games in young soccer players. Journal of Human Kinetics, 31, 89-96. https://doi.org/10.2478/v10078-012-0009-5

Köklü, Y., \& Alemdaroğlu, U. (2016). Comparison of the Heart Rate and Blood Lactate Responses of Different Small Sided Games in Young Soccer Players Sports, 4(4), 48-55.

Köklü, Y., Özkan, A., \& Ersöz, G. (2009). The assessment and development of endurance performance in soccer, Celal Bayar University, 4(3), 142-50.

Little, T., \& Williams, A. G. (2006). Suitability of soccer training drills for endurance training. J Strength Cond Res, 20, 316-19.

Rampinini, E., Impellizzerri, F. M., Castagna, C., Abt, G., Chamari, K., Sassi, A., \& Marcora, S. M. (2007). Factors influencing physiological responses to small-sided games, $J$ Sport Sci, 25, 650-66. https://doi.org/10.1080/02640410600811858

Rebecca, T., \& Fuller, R. (2010). Evaluation of three portable blood lactate analysers: Lactate Pro,Lactate Scout and 
Lactate Plus, Eur J Appl Physiol, 109, 551-559. https://doi.org/10.1007/s00421-010-1379-9

Tamer, K. (2013). The Measurement and Assessment of Physical Physiological Performance in Sport, 2nd Edition, Ankara, Gazi Publication.

\section{Copyrights}

Copyright for this article is retained by the author(s), with first publication rights granted to the journal.

This is an open-access article distributed under the terms and conditions of the Creative Commons Attribution license which permits unrestricted use, distribution, and reproduction in any medium, provided the original work is properly cited. 